\title{
Erratum to: Design considerations for a theory-driven exergame-based rehabilitation program to improve walking of persons with stroke
}

Seline Wüest • Rolf van de Langenberg •

Eling D. de Bruin

Published online: 22 May 2014

(C) European Group for Research into Elderly and Physical Activity (EGREPA) 2014

Erratum to: Eur Rev Aging Phys Act

DOI 10.1007/s11556-013-0136-6

The original publication of this article stated that "Worldwide, there are about 4.8 million survivors of stroke of whom about 1.1 million suffer lasting functional disabilities (DeJong et al. 2005)."

However, this should instead read "In the United States of America, there are about 4.8 million survivors of stroke of whom about 1.1 million suffer lasting functional disabilities (DeJong et al. 2005)."

The online version of the original article can be found at http://dx.doi.org/ 10.1007/s11556-013-0136-6.

S. Wüest $(\bowtie) \cdot R$. van de Langenberg $\cdot$ E. D. de Bruin Department of Health Sciences and Technology, Institute of Human Movement Sciences and Sport, Wolfgang-Pauli-Str. 27, 8093 Zurich, Switzerland

e-mail: seline.wueest@hest.ethz.ch

R. van de Langenberg

e-mail: rvdlangenberg@ethz.ch

E. D. de Bruin

e-mail: eling.debruin@hest.ethz.ch

S. Wüest $\cdot$ R. van de Langenberg $\cdot$ E. D. de Bruin

ETH Zurich, Zurich, Switzerland 